\title{
Tanshinone IIA inhibits glucose metabolism leading to apoptosis in cervical cancer
}

\author{
ZHIGANG LIU $^{1 *}$, WENHE ZHU ${ }^{2 *}$, XIANGYU KONG ${ }^{1}$, XI CHEN $^{1}$, \\ XINYI SUN ${ }^{1}$, WEI ZHANG ${ }^{2}$ and RUOWEN ZHANG ${ }^{1}$ \\ ${ }^{1}$ Faculty of Medicine, Beihua University; ${ }^{2}$ Department of Biochemistry, Jilin Medical University, Jilin, Jilin 132013, P.R. China
}

Received February 13, 2019; Accepted July 16, 2019

DOI: $10.3892 / o r .2019 .7294$

\begin{abstract}
Cancer requires aerobic glycolysis to supply the energy required for proliferation. Existing evidence has revealed that blocking glycolysis results in apoptosis of cancer cells. Tanshinone IIA (Tan IIA) is a diterpenoid naphthoquinone found in traditional Chinese medicine, Danshen (Salvia sp.). Tan IIA exhibits potential anticancer activity. However, its effect on cell viability of human cervical cancer cells and its mechanism are unknown. The aim of the present study was to determine the effect of Tan IIA on proliferation and glucose metabolism in cervical cancer cells. Cell viability was measured by MTT assay, apoptosis was determined using flow cytometry and glucose uptake, lactate production, and adenosine triphosphate content were measured to assess glucose metabolism. The expression of apoptosis-associated proteins was detected by western blotting and the antitumor activity of Tan IIA in vivo was evaluated in cervical carcinoma-bearing mice. The results revealed Tan IIA treatment resulted in a considerable reduction in the viability of SiHa cells. Tan IIA decreased the expression of HPV oncogenes E6 and E7, induced apoptosis and also decreased glycolysis by
\end{abstract}

Correspondence to: Dr Ruowen Zhang, Faculty of Medicine, Beihua University, 3999 Binjiang East Road, Jilin, Jilin 132013, P.R. China

E-mail: zrw1828@163.com

Dr Wei Zhang, Department of Biochemistry, Jilin Medical University, 5 Jilin Street, Jilin, Jilin 132013, P.R. China

E-mail: jlmpczw@163.com

*Contributed equally

Abbreviations: Akt, protein kinase B; DMEM, Dulbecco's Modified Eagle's Medium; DMSO, dimethyl sulfoxide; FBS, fetal bovine serum; GLUT1, glucose transporter 1; HIF-1 $\alpha$, hypoxia-inducible factor-1 $\alpha$; HPVs, human papillomaviruses; p38, p38 mitogen-activated protein kinases; PI3K, phosphatidylinositol-4, 5-bisphosphate 3-kinase; qRT-PCR, quantitative reverse transcription PCR; MTT, 3-(4,5-dimethylthiazol-2-yl)-2,5-diphenyltetrazolium bromide; Tan IIA, tanshinone II

Key words: tanshinone IIA, glycolysis, apoptosis, cervical cancer suppressing the activity of the intracellular AKT/mTOR and HIF-1 $\alpha$. In vivo, treatment with Tan IIA resulted in a $72.7 \%$ reduction in tumor volume. The present study highlights the potential therapeutic value of Tan IIA, which functions by inducing apoptosis and may be associated with inhibition of glycolysis.

\section{Introduction}

Cervical cancer is one of the most common malignant carcinomas amongst women worldwide. There are an estimated 530,000 new cases of cervical cancer annually with 270,000 cancer-related deaths $(1,2)$. Infection with high-risk human papillomaviruses (HPVs), such as HPV16 and HPV18, is the primary cause of cervical cancer, amongst multiple factors (3). Understanding that HPV infection is the primary inducer of development of cervical cancer has improved prevention of cervical cancer (4). At present, the strategies for treatment of cervical cancer include surgery, radiation and chemotherapy. However, the severe systemic toxicity caused by radiation and chemotherapy affect prognosis (4-7). Therefore, developing a safe therapeutic strategy for cervical cancer treatment is desirable.

Isolating components of traditional medicines with antineoplastic activities has been demonstrated as a promising alternative strategy for treating patients with cancer $(8,9)$. Tanshinone II A (Tan IIA) is the primary lipophilic component isolated form the traditional Chinese medicine Salvia miltiorrhiza. Numerous animal and clinical studies have demonstrated that Tan IIA is an effective reagent commonly used for the prevention and treatment of cardiovascular diseases, including atherosclerosis via its antioxidant and anti-inflammatory activities (10-12). Tan IIA has recently attracted considerable attention in cancer therapy due to its potential antitumor activities. The antitumor effect of Tan IIA has been verified in various cancer cell lines, including glioma, osteosarcoma, leukemia, prostate, breast, colon, lung, liver, stomach, pancreas, bile duct, kidney, ovarian, cervical and nasopharyngeal cells (13-16). Studies have demonstrated that Tan IIA may suppress the growth and induce apoptosis in certain types of cancer cells through multiple mechanisms, including cell cycle arrest and caspase-dependent apoptosis $(17,18)$. However, the antitumor mechanisms of Tan IIA remain unknown. 
Over the last decade, advances in understanding of the metabolism in cancer cells has revealed that cancer cells predominantly rely on aerobic glycolysis to maintain cell proliferation $(19,20)$. Inhibition of aerobic glycolysis in tumors has been identified as an effective strategy to aid in overcoming obstacles in cancer treatment, and the effectiveness of this approach has been validated in pre-clinical studies (21). Inhibiting glycolysis in a tumor may be an effective treatment strategy for potential future treatments (22-24).

Several studies have reported that Tan IIA inhibits proliferation in cervical cancer cells by inducing apoptosis in these cells $(25,26)$. However, previous research has only focused on the use of Tan IIA to induce tumor cell apoptosis. The role of Tan IIA on inhibition of glycolysis in cervical cancer has not been studied. The aim of the present study was to examine the effect of Tan IIA on cell growth in cervical cancer and determine the underlying mechanism, by assessing change in metabolic phenotype and apoptosis. The present study provides insight into the molecular mechanism through which Tan IIA induces apoptosis in cervical cancer and highlights the potential use of Tan IIA as a novel therapeutic agent for treating patients with cervical cancer.

\section{Materials and methods}

Materials. Human cervical cancer cell lines SiHa (HPV 16-positive cells), HeLa (HPV 18-positive cells) and C33a (HPV negative) were provided by the Chinese Academy of Sciences (Shanghai, China). Dulbecco's Modified Eagle's Medium (DMEM) and fetal bovine serum (FBS) were purchased from Thermo Fisher Scientific, Inc. Dimethyl sulfoxide (DMSO, analytical grade) was obtained from Beijing Chemical Reagent Factory. Tan IIA was obtained from PhytoMyco, Inc. The mouse anti-human Bcl-2 antibody (cat. no. sc-23960), mouse anti-human Bax antibody (cat. no. sc-20067), rabbit ant-human cleaved caspase-3 antibody (cat. no. sc-7148), mouse anti-human cleaved caspase-9 antibody (cat. no. sc-17784), mouse anti-human cytochrome $c$ antibody (cyto $c$; cat. no. sc-13561) were obtained from Santa Cruz Biotechnology, Inc. Rabbit ant-human p-AKT antibody (ID product code ab18206), rabbit ant-human AKT antibody (ID product code ab8805), rabbit ant-human p-mTOR antibody (ID product code ab84400), rabbit ant-human mTOR antibody (ID product code ab2732) were obtained from Abcam, Inc. Rabbit ant-human GLUT1 antibody (cat. no. PA5-16793), rabbit ant-human PKM2 antibody (cat. no. PA5-23034), rabbit ant-human HK2 antibodies (cat. no. PA5-29326) were purchased from Invitrogen; Thermo Fsiher Scientific, Inc.

Cell culture. $\mathrm{SiHa}, \mathrm{HeLa}$ and $\mathrm{C} 33 \mathrm{a}$ cells were maintained in DMEM supplemented with $10 \%$ FBS, 100 units $/ \mathrm{ml}$ of penicillin and $100 \mathrm{units} / \mathrm{ml}$ of streptomycin at $37^{\circ} \mathrm{C}$ in a humidified atmosphere of 5\% carbon dioxide $\left(\mathrm{CO}_{2}\right)$ and $95 \%$ air. Cells were sub-cultured every three days with $0.25 \%$ trypsin.

Cytotoxicity assay. The cytotoxicity of Tan IIA on tumor cells was detected by MTT assay (27). SiHa, HeLa and C33a cells were seeded into a 96-well assay plate with a concentration $1.0 \times 10^{5} \mathrm{cells} / \mathrm{ml}(200 \mu \mathrm{l} / \mathrm{well})$. After $24 \mathrm{~h}$ of incubation, the cells were treated with Tan IIA with doses of $0-8 \mathrm{mg} / \mathrm{l}$ in the growth medium. Each concentration was assessed five times. The cells were cultured for another 24,48 and $72 \mathrm{~h}$. Subsequently, $20 \mu \mathrm{l}$ of MTT $(5 \mathrm{mg} / \mathrm{ml})$ was added to each well and incubated for another $4 \mathrm{~h}$. Then, supernatant was discarded and $150 \mu \mathrm{l}$ DMSO was loaded to each well. The optical density (OD) was measured at $490 \mathrm{~nm}$ using a Bio-assay reader (Bio-Rad 550; Bio-Rad Laboratories, Inc.).

Quantitative reverse transcription PCR ( $q R T-P C R)$. The total RNA form Tan IIA-treated and untreated $\mathrm{SiHa}$ cells were extracted to detect the expression of HPV16-E6/E7 gene. Total cellular RNA was isolated using TRIzol reagent (Invitrogen; Thermo Fisher Scientific, Inc.) as per the manufacturer's protocol. A high-capacity cDNA reverse-transcription kit was used to prepare cDNA (Thermo Fisher Scientific, Inc). qRT-PCR was carried out using gene-specific oligonucleotide primers (Table I), an iScript One-Step RT-PCR kit with SYBR-Green and an ABI 7500 Fast real-time PCR system. The PCR conditions were set as $95^{\circ} \mathrm{C}$ for $5 \mathrm{~min}$, followed by 40 cycles at $95^{\circ} \mathrm{C}$ for $30 \mathrm{sec}, 60^{\circ} \mathrm{C}$ for $45 \mathrm{sec}$ and $72^{\circ} \mathrm{C}$ for $30 \mathrm{~min}$. All values were normalized to $\beta$-actin and then standardized to the control condition. Error bars represent the standard error of the mean (SEM), and the statistical significance was assessed using the Student's t-test. After completion of the RT-PCR, Cq values were obtained using the ABI 7500 fast v2.0.1 software. The $\Delta \Delta \mathrm{Cq}$ method was used to represent mRNA fold change (28).

Fluorescence microscope-detected apoptosis. SiHa cells were cultured on slides at a density of $5 \times 10^{4} / \mathrm{ml}$ in 24 -well plates. After Tan IIA treatment, the medium was removed and the cells were washed with PBS twice. Then, the cells were fixed with $4 \%$ paraformaldehyde for $10 \mathrm{~min}$ at $25^{\circ} \mathrm{C}$. Subsequently, the cells were stained with Hoechst 33258 for 5 min at $25^{\circ} \mathrm{C}$. The apoptosis morphology was observed using a fluorescence microscope. The images were captured at magnifications of $\mathrm{x} 200$.

Flow cytometric evaluation of apoptosis. After Tan IIA treatment, SiHa cells were harvested by centrifugation at $1,000 \mathrm{xg}$ for 3 min and washed with PBS twice. After that the harvested cells pellet was resuspend in $100 \mu \mathrm{l}$ DMEM medium. Then $100 \mu 1$ Muse Annexin V and Dead Cell reagents were added and incubated at room temperature for $20 \mathrm{~min}$. The percentage of apoptosis was detected and analyzed using a Muse Cell Analyzer (EMD Millipore).

Caspase-3/7 activation detected. The caspase-3/7 activation change was detected by Muse Cell Analyzer following the manufacturer's instructions. After Tan IIA treatment, SiHa cells were harvested by centrifugation at $850 \mathrm{x} \mathrm{g}$ and the cell pellet was resuspended in $50 \mu \mathrm{l}$ PBS. Muse Caspase-3/7 reagent working solution $(5 \mu \mathrm{l})$ was added to the cell suspension, and it was mixed thoroughly and incubated at $37^{\circ} \mathrm{C}$ for 30 min. After incubation, $150 \mu 1$ of Muse ${ }^{\mathrm{TM}}$ Caspase 7-AAD working solution was loaded to each sample, and incubated at room temperature for $5 \mathrm{~min}$. Then, the caspase-3/7 activation was detected by Muse Cell Analyzer.

Measurements of glucose uptake levels and lactate production. The SiHa cells were seeded in 6-well plates at a density of 
Table I. Sequences of primers for qRT-PCR.

\begin{tabular}{lcl}
\hline Gene & Forward primer & \multicolumn{1}{c}{ Reverse primer } \\
\hline E6 & GAGCGACCCAGAAAGTTACCA & AAATCCCGAAAAGCAAAGTCA \\
E7 & CATGGAGATACACCTACATTGC & CACAACCGAAGCGTAGAGTC \\
\hline
\end{tabular}

$1 \times 10^{4}$ cells/well. After treatment with Tan IIA for $48 \mathrm{~h}$, the cell culture media was collected to detect the glucose uptake and lactate production. For assessment of lactate production, the collected culture media was diluted 1:50 by using lactate assay buffer. The amount of lactate present in the media was then estimated using the Lactate Assay kit (Sigma-Aldrich; Merck KGaA) according to the manufacturer's instructions. The content of glucose in the collected culture media was detected immediately using a Glucose Assay kit according to the manufacturer's instructions. Glucose uptake and lactate production were all normalized by cell number (29).

Determination of ATP content. SiHa cells were seeded in 6 -well plates $\left(1 \times 10^{5}\right.$ cells $\left./ \mathrm{ml}\right)$ and then incubated with Tan IIA for $48 \mathrm{~h}$. Then, the cells were harvested and lysed on ice with somatic cell ATP releasing reagent. The ATP content was detected by ATP assay kits (Genmed Scientifics, Inc.) according to the manufacturer's instructions. ATP content was normalized by cell number (29).

Western blot analysis. After Tan IIA treatment, $5 \times 10^{5} \mathrm{SiHa}$ cells were harvested and lysed in RIPA buffer (Sigma-Aldrich; Merck KGaA) to extract the total protein. The extract total protein content was determined by Bio-Rad BCA protein assay kit and $50 \mu \mathrm{g}$ protein/lane was loaded on $12 \%$ SDS-PAGE. After SDS-PAGE, the separated proteins were transferred to nitrocellulose membranes. Non-specific binding was blocked by incubating nitrocellulose membranes in 5\% non-fat dry milk in TBS/0.1\% Tween for 120 min. After blocking, the blots were incubated with primary antibody: Bcl-2 antibody (dilution 1:2,000), Bax (dilution 1:2,000), cleaved caspase-3 (dilution 1:2,000), cleaved caspase-9 (dilution 1:2,000), cyto $c$ antibody (dilution 1:2,000), p-AKT (dilution 1:1,000), AKT (dilution 1:1,000), p-mTOR (dilution 1:1,000), mTOR (dilution 1:1,000), GLUT1 (dilution 1:1,000), PKM2 (dilution 1:1,000), HK2 (dilution $1: 1,000$ ) at $4^{\circ} \mathrm{C}$ overnight. Then, the appropriate secondary antibody (cat. nos. sc-2357 and sc-516132; Santa Cruz Biotechnology) at a 1:5,000 dilution was added and incubation followed for $1 \mathrm{~h}$ at room temperature. Immunoreactive protein bands were detected by chemiluminescence using enhanced chemilumunescence reagents (ECL) was obtained from Santa Cruz Biotechnology, Inc. Blots were also stained with anti- $\beta$-actin antibody (cat. no. 60008-1-Ig; Proteintech Group) as an internal control for the amounts of target proteins. The films were then subjected to densitometry analysis using a Gel Doc 2000 system (Bio-Rad Laboratories, Inc.).

In vivo antitumor test. All animal experiments were performed in compliance with the guidelines of the Ethics Committee for Animal Use and Care of Beihua University. This committee approved the experiments in the present study. Kunming (KM) female mice $(n=25)$ were purchased from Jilin University (8 weeks old; $20-25 \mathrm{~g}$ ). The animals were maintained under a dedicated room with a 12-h light/dark cycle at a constant temperature of $22^{\circ} \mathrm{C}$.

First, U14 cervical cancer cells obtained from The Chinese Academy of Sciences (Shanghai, China) were harvested by trypsin digestion, washed by PBS, and re-suspended in serum-free RPMI-1640 medium. U14 cervical cancer cell suspension $(0.2 \mathrm{ml})$ with a density of $5 \times 10^{6}$ was injected into the right infra-axillary dermis of the mice. When the size of the tumor reached $150 \mathrm{~mm}^{3}$, the mice were randomly assigned to 5 groups with 5 mice in each group: Control, cyclophosphamide (CTX; $25 \mathrm{mg} / \mathrm{kg} / \mathrm{day}$, i.g.), and three doses of Tan IIA (40 mg/kg/day; $20 \mathrm{mg} / \mathrm{kg} /$ day; and $10 \mathrm{mg} / \mathrm{kg} /$ day). The tumor volume and body weight were measured every two days for 14 days. The relative tumor volume $\mathrm{V}_{\mathrm{t}} / \mathrm{V}_{0}$ as a function of time was used to investigate the inhibitory effect. All groups were treated every two days for 20 days, and $24 \mathrm{~h}$ after the last administration, the mice of the four groups were sacrificed. The tumors were excised to evaluate tumor inhibition. The tumor inhibition rate was calculated by the formula: Inhibitory rate $(\mathrm{IR})=$ (the tumor weight of the control group - the tumor weight of the treated group/the tumor weight of the control group) $x 100 \%$. For euthanasia, animals were anesthetized with $5 \%$ isoflurane vaporized in oxygen and thereafter euthanatized with a $20 \%$ container volume/min gas replacement rate of carbon dioxide. Euthanasia was confirmed when the heartbeat stopped and the pupils were enlarged.

Histopathological and morphological examination. The tumor tissues were excised and fixed at $25^{\circ} \mathrm{C}$ for one week in $4 \%$ formalin, embedded in paraffin, and cut into $4-\mathrm{mm}$ sections for histological study. Hematoxylin and eosin (H\&E) purchased form Sigma-Aldrich (Merck KGaA) was used to stain the tumor for histological analysis. Histopathological analysis of the tumor tissue sections was performed using a light microscope at an $\mathrm{x} 200$, magnification.

Statistical analysis. Results are presented as the mean \pm SEM which are derived from three or more independent experiments. All data were analyzed by one-way ANOVA using SPSS version 13 software (SPSS, Inc.). Tukey's post hoc test was used to determine the significance for all pairwise comparisons of interest. A value of $\mathrm{P}<0.05$ was considered to indicate a statistically significant difference.

\section{Results}

Tan IIA inhibits the cell viability against human cervical cancer cells. An MTT assay was performed to determine the cytotoxicity of Tan IIA in SiHa, HeLa, and C33a cells after 
A

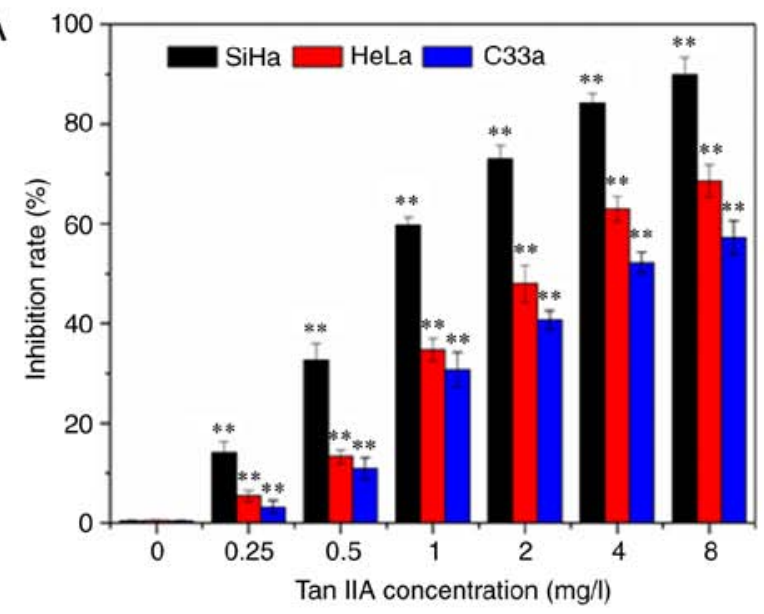

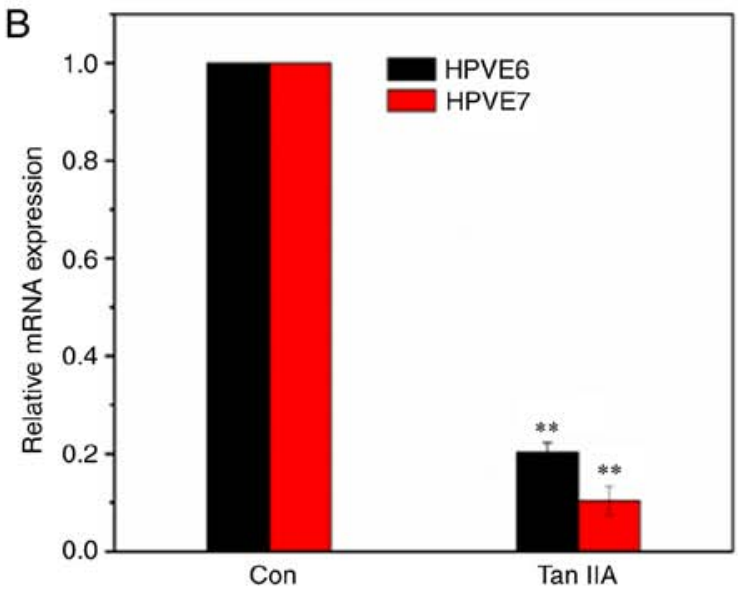

D

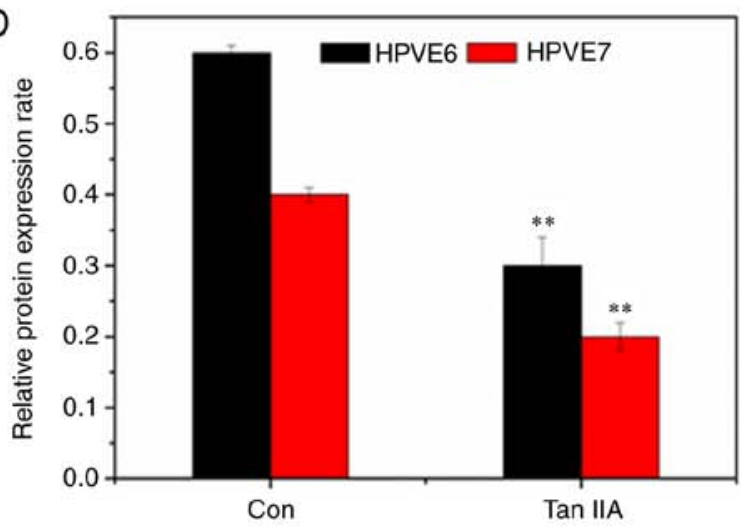

Figure 1. Tan IIA inhibits the cell viability of human cervical cancer cells and decreases the expression of HPV oncogenes. (A) Tan IIA inhibited the cell viability of $\mathrm{SiHa}, \mathrm{HeLa}$, and $\mathrm{C} 33 \mathrm{a}$ cells in a dose-dependent manner. Cells were treated with increasing concentrations $(0,0.25,0.5,1,2,4$ and 8 mg/l) of Tan IIA for $48 \mathrm{~h}$. Cell viability was assessed using an MTT assay. (B) Effect of Tan IIA on the mRNA expression levels of HPV16 E6 and E7 in SiHA cells. (C) Western blotting revealed the expression of HPV oncogenes in SiHa cells treated with Tan IIA. (D) Densitometry analysis of the blots presented in C. Data are presented as the mean \pm standard deviation (SD), $n=5 .{ }^{* *} \mathrm{P}<0.01$ compared with the control. Tan IIA, tanshinone IIA; HPV, human papillomavirus.

$48 \mathrm{~h}$ of treatment. The results revealed that Tan IIA significantly inhibited cell viability in SiHa, HeLa and C33a cells in a dose-dependent manner (Fig. 1A). Tan IIA had a greater inhibitory effect on cell viability in $\mathrm{SiHa}$ and HeLa cells compared with the HPV-negative C33a cells. Thus, SiHa cells were used for all subsequent experiments.

Tan IIA suppresses HPV16-E6/E7 gene expression. The effect of Tan IIA expression on mRNA expression of HPV16-E6/E7 in SiHa cells was determined using reverse transcription-quantitative (RT-q)PCR (Fig. 1B). Treatment with Tan IIA $(1.5 \mathrm{mg} / \mathrm{l})$ resulted in a significant reduction in the mRNA expression of HPV E6 and HPV E7. Western blot analysis also confirmed the results of the RT-qPCR (Fig. 1C).

Tan IIA induces SiHa cell apoptosis. Hoechst 333258 was used to stain apoptotic nuclei. Hoechst 333258 staining revealed that the nuclei appeared as uniform blue with organized chromatin structure in the control group (Fig. 2A). Following treatment with Tan IIA at a range of concentrations $(0.5,1$ and $2 \mathrm{mg} / \mathrm{l})$ for $48 \mathrm{~h}$, the SiHa cells were decreased in number and presented with smaller nuclei, strong fluorescent spots, pyknotic nuclei and extensive blebbing. Condensed chromatin and apoptotic bodies were observed under a fluorescence microscope in the treated cells suggesting that the Tan IIA treatment had induced apoptosis in the SiHa cells. Similar results were obtained from staining with Muse Annexin $\mathrm{V}$ and Dead Cell reagents. As revealed in Fig. $2 \mathrm{~B}$ and $\mathrm{C}$ the percentage of early apoptotic cells was increased as the dose of Tan IIA increased compared with the untreated group $(\mathrm{P}<0.01)$.

Detection of caspase-3/7 activation. Muse caspase-3/7 assay kits were used to detect caspase-3/7 activation following treatment with Tan IIA in the SiHa cells. Stained cells were quantified using a Muse cell analyzer. The percentage of cells in early apoptosis was $4.9,10.55$, and $22.55 \%$ when treated with $0.5,1$ and $2 \mathrm{mg} / 1$ Tan IIA, respectively (Fig. 2D and E).

Inhibitory effect of Tan IIA on glucose uptake, lactate generation, and adenosine triphosphate (ATP) production. Tumor cells use glucose as a substrate for ATP synthesis and production. Glucose uptake in SiHa cells following treatment with Tan IIA for $48 \mathrm{~h}$ was measured. The results revealed that glucose uptake in Tan IIA-treated SiHa cells was decreased (Fig. 3A). The primary product of aerobic glycolysis is lactic acid and ATP. Thus, the ATP and lactic acid content were measured using reagent kits to investigate whether glycolysis inhibition was associated with Tan IIA-mediated SiHa cell apoptosis. The results revealed that the levels of intracellular ATP and extracellular lactic acid were decreased in SiHa cells treated with Tan IIA $(0.5,1$ and $2 \mathrm{mg} / \mathrm{l})$ compared with the control group (Fig. 3B and C). 
A

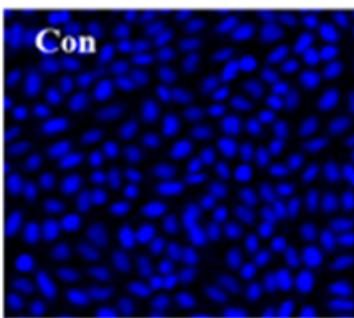

$1 \mathrm{mg} / \mathrm{L}$

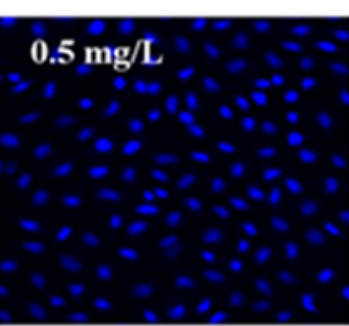

$2 \mathrm{mg} / \mathrm{L}$

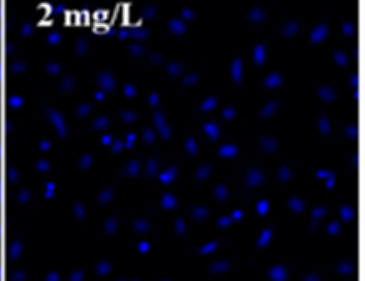

C

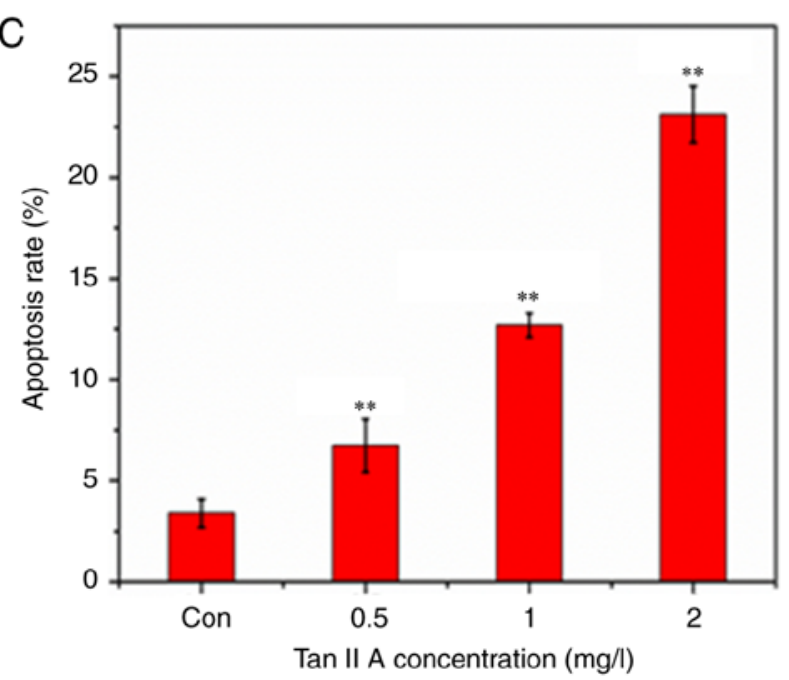

B
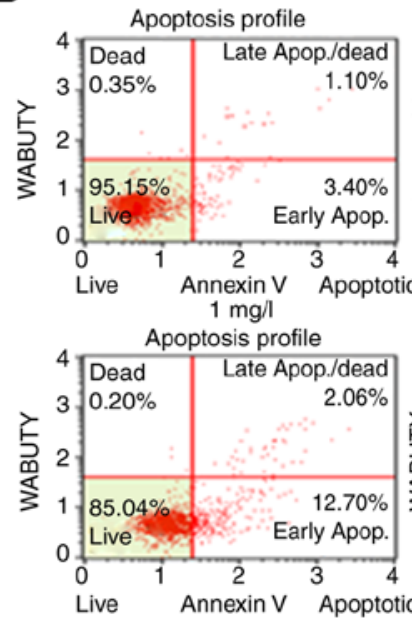

Con

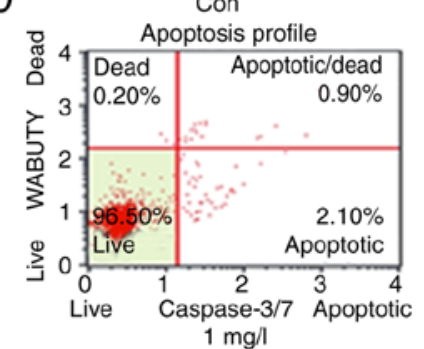

סू 4 Apoptosis profile

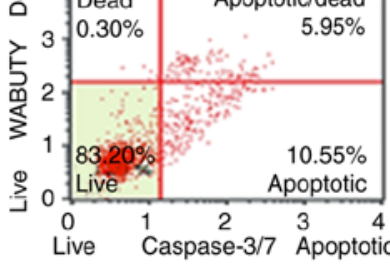

$0.5 \mathrm{mg} / \mathrm{l}$

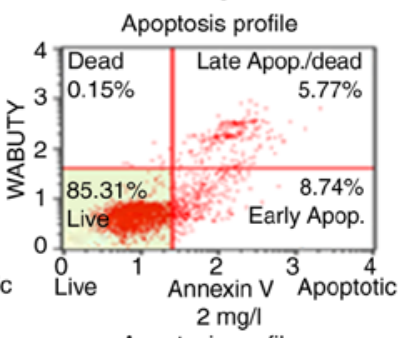

Apoptosis profil

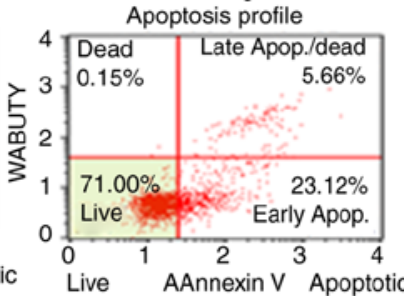

$0.5 \mathrm{mg} / \mathrm{l}$
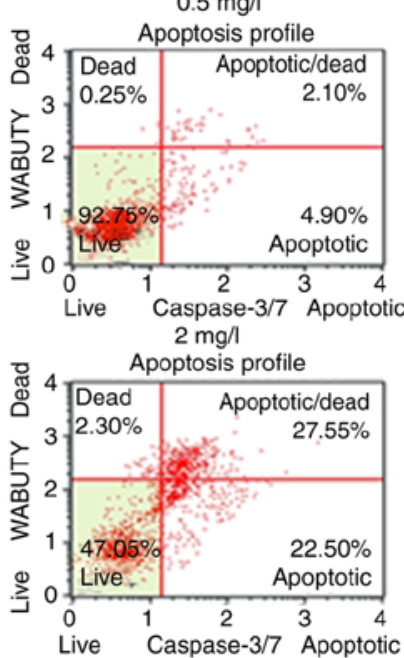

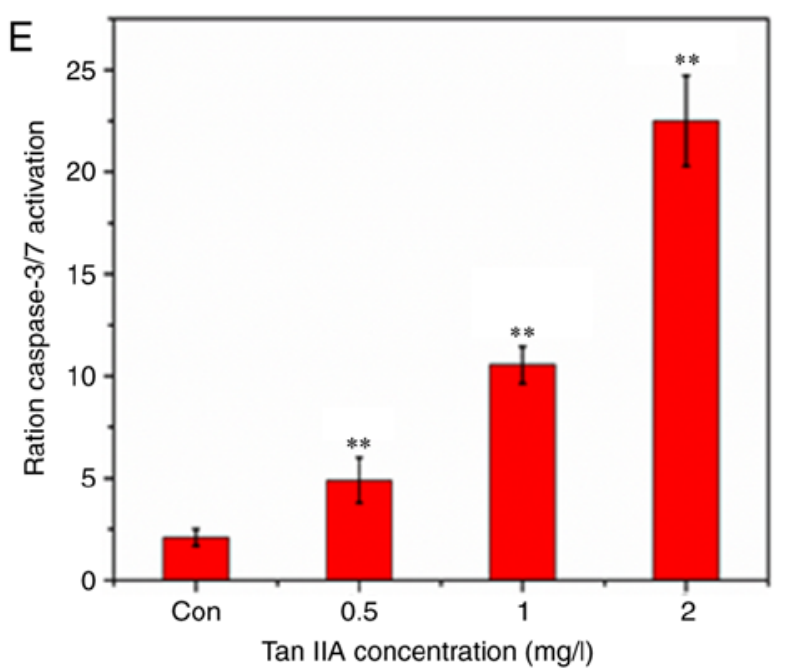

Figure 2. Effect of Tan IIA on apoptosis and and caspase-3/7 activation in SiHa cells. (A) Following treatment with increasing concentrations of Tan IIA for $48 \mathrm{~h}$, SiHa cells were stained with Hochest 33258, and the morphology was observed using a fluorescence microscope. Magnification, x200. (B) SiHa cells were treated with different concentrations of Tan IIA, and apoptosis was assessed using a Muse Cell Analyzer. (C) Quantification of apoptotic cells. (D) Analysis of caspase-3/7 activation in cells treated with Tan IIA using a cell analyzer. (E) Quantification of caspase-3/7 activation. Data are presented as the mean $\pm \mathrm{SD}, \mathrm{n}=5$. $^{* *} \mathrm{P}<0.01$ compared with the control. Tan IIA, tanshinone IIA.

Tan IIA induces SiHa cell apoptosis through the mitochondrial apoptosis pathway. Western blotting was used to assess the expression of apoptosis-associated proteins in Tan IIA-treated
SiHa cells to determine which apoptosis pathway underlied Tan IIA activity in apoptosis of cervical cancer cells. As revealed in Fig. 4, after treatment with increasing doses 

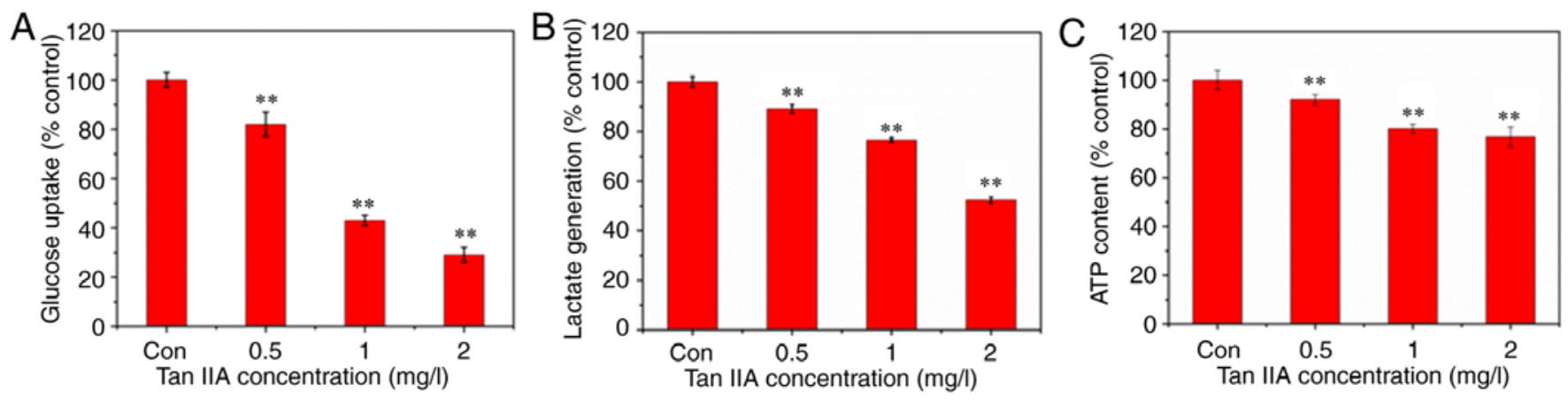

Figure 3. Tan IIA decreases the rate of glycolysis in SiHa cells. (A) Following treatment with increasing concentrations of Tan IIA for 48 h, the glucose content in the culture media was assessed, and glucose uptake was calculated. (B) Measurement of lactate content. (C) ATP content was detected using a bioluminescence assay. Data are presented as the mean $\pm \mathrm{SD}, \mathrm{n}=5$. $^{* *} \mathrm{P}<0.01$ compared with the control. Tan IIA, tanshinone IIA.

A

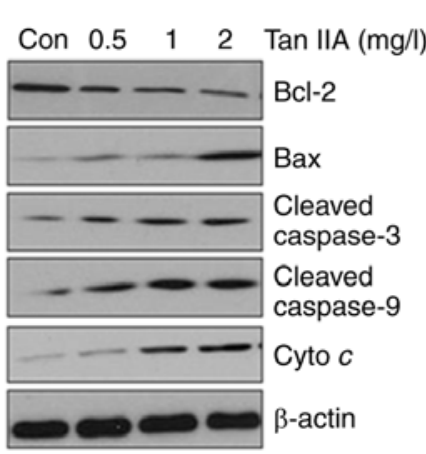

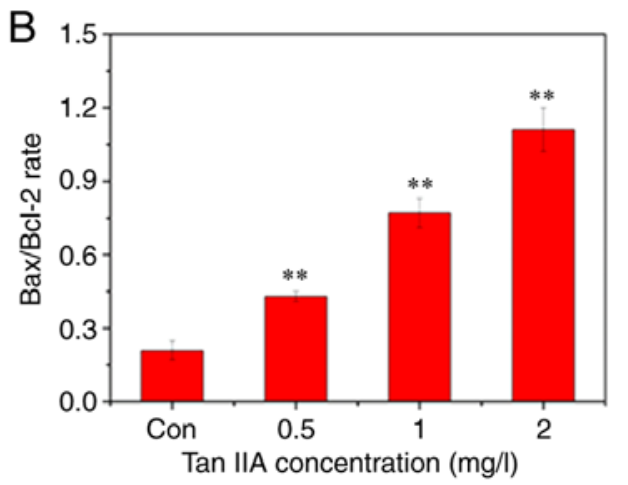

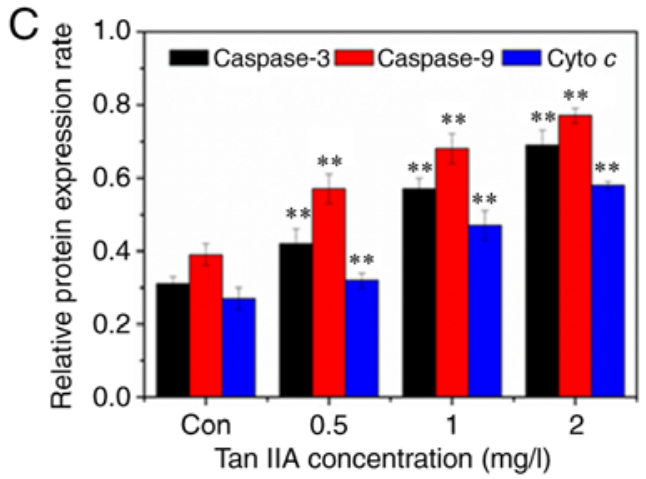

Figure 4. Tan IIA activates cleavage of caspase-3 and caspase-9, and upregulates the expression of cyto $c$ and Bax, and decreases the expression of Bcl-2 in $\mathrm{SiHa}$ cells. (A) SiHa cells treated with Tan IIA for $48 \mathrm{~h}$ were havested for western blot analysis to assess the protein expression levels of apoptosis-associated proteins. (B) Quantitation of Bax/Bcl-2. (C) Densitometric values were normalized by $\beta$-actin and expressed as the mean $\pm \mathrm{SD}$, $\mathrm{n}=3$. ${ }^{* *} \mathrm{P}<0.01 \mathrm{compared}$ with the control. Tan IIA, tanshinone IIA.

of Tan IIA for $48 \mathrm{~h}$, the expression levels of Bax, cleaved caspase- 3 and cleaved caspase- 9 were significantly increased. Bcl-2 expression signficantly decreased. Thus, there was a dose-dependent increase in the expression ratio of $\mathrm{Bax} / \mathrm{Bcl}-2$. In the Tan IIA-treated SiHa cells, cyto $c$ was released from the mitochondria to the cytosol in a dose dependent manner.

Tan IIA downregulates the Akt/mTOR signaling pathway and inhibits glycolysis. The expression of GLUT1 was detected by western blotting. The western blot results revealed that Tan IIA decreased the expression of GLUT1, PKM2, and HK2 (Fig. 5), confirming inhibition of glycolysis in SiHa cells treated with Tan IIA. The AKT/mTOR pathway serves a major role in the activation of aerobic glycolysis in tumors. Therefore, it was determined whether the AKT/mTOR signaling pathway was involved in regulation of aerobic glycolysis in the Tan IIA-treated SiHa cells. Treatment with Tan IIA resulted in a dose-dependent decrease of the phosphorylation of Akt and mTOR (Fig. 6). HIF-1 $\alpha$ mediates transformation of cell metabolism, whereas the PI3K/AKT pathways are involved in the regulation of HIF-1 $\alpha$. As revealed in Fig. 6, Tan IIA inhibited the expression of HIF-1 $\alpha$ in SiHa cells.

Effect of Tan IIA on tumor growth in vivo. U14 tumor-bearing Kunming mice were used to determine the antitumor effects of Tan IIA in vivo. When the the tumor size of mice reached
$150 \mathrm{~mm}^{3}$, they were randomly divided into 5 groups. Mice were intraperitoneally administered with CTX $(25 \mathrm{mg} / \mathrm{kg})$ and Tan IIA (three doses) for 14 days. As revealed in Fig. 7A, the tumor in the control group grew rapidly, whereas the tumors in the mice treated with CTX and Tan IIA grew significantly slower. The body weight of the mice in the Tan IIA-treated group gradually increased but did not significantly differ from the control group, suggesting that Tan IIA did not demonstrate any significant toxic effect. At the end of the experiment, the mice were sacrificed, and the size of the tumors and tumor weights were measured. The results revealed that the tumor weight and volume in the CTX- and Tan IIA-treated groups decreased compared with the control group, in which the high dose of Tan IIA resulted in mice with a tumor weight similar to that in the CTX-treated group. The diameter of the tumor in each group is revealed in Table SI. The maximum tumor volume in each group is revealed in Table SII. The tumor inhibition rate in the CTX-treated group was $65.1 \%$, whereas the rate in mice treated with a high dose (40 mg/kg/day) of Tan IIA was $72.7 \%$ (Fig. 7C and D and Table SIII). Pathological analysis of the tumor tissues revealed that tumors in the U14 model group exhibited invasive growth and rapid diffusion with high degrees of tumor cell proliferation. CTX-treated tumor cells exhibited unclear structures with regional necrosis, clear cell edema and a large number of disintegrated granular cells. Following treatment 
A

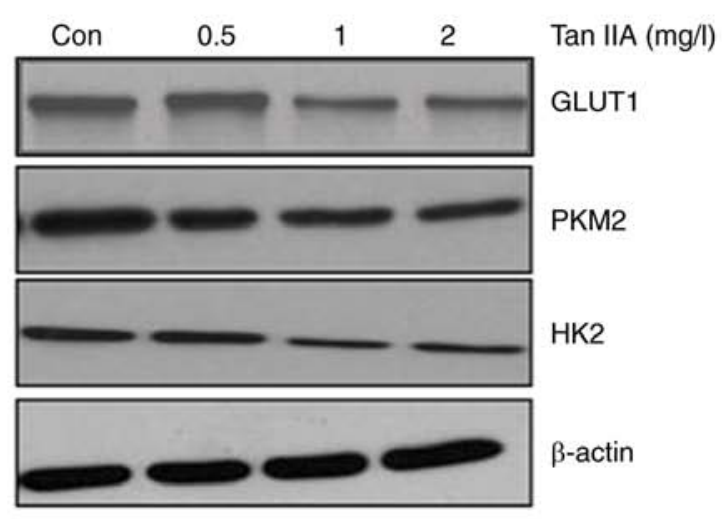

B

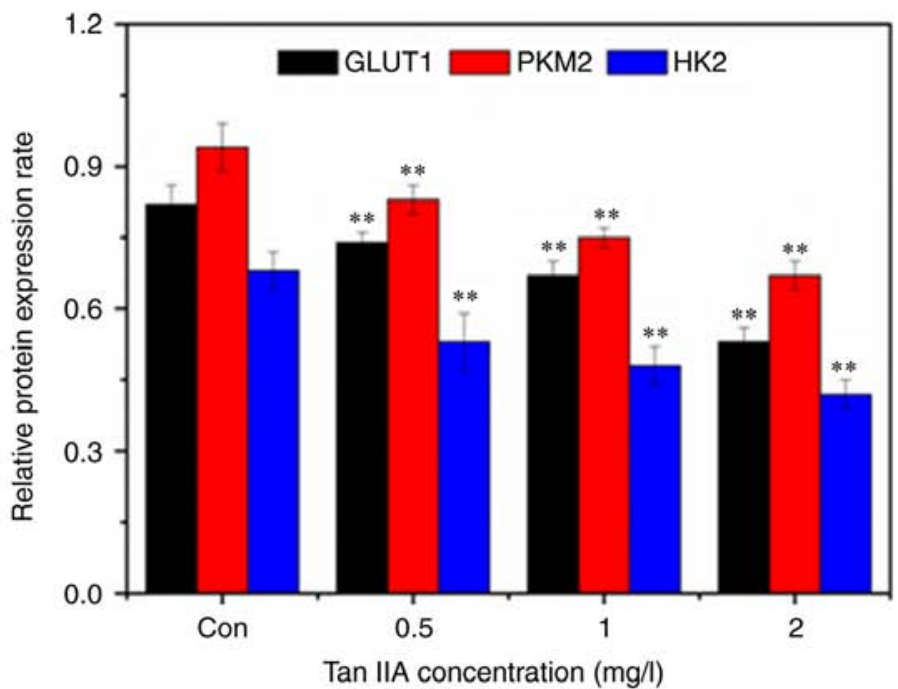

Figure 5. Tan IIA-induces changes in the expression of GLUT1, PKM2 and HK2 in SiHa cells. (A) Following treatment with Tan IIA for $48 \mathrm{~h}$, the expression of GLUT1, PKM2, and HK2 was assessed by western blot analysis. (B) Densitometric values were normalized by $\beta$-actin and expressed as the mean \pm SD, $\mathrm{n}=3$. ${ }^{* *} \mathrm{P}<0.01$ compared with the control. Tan IIA, tanshinone IIA.

A
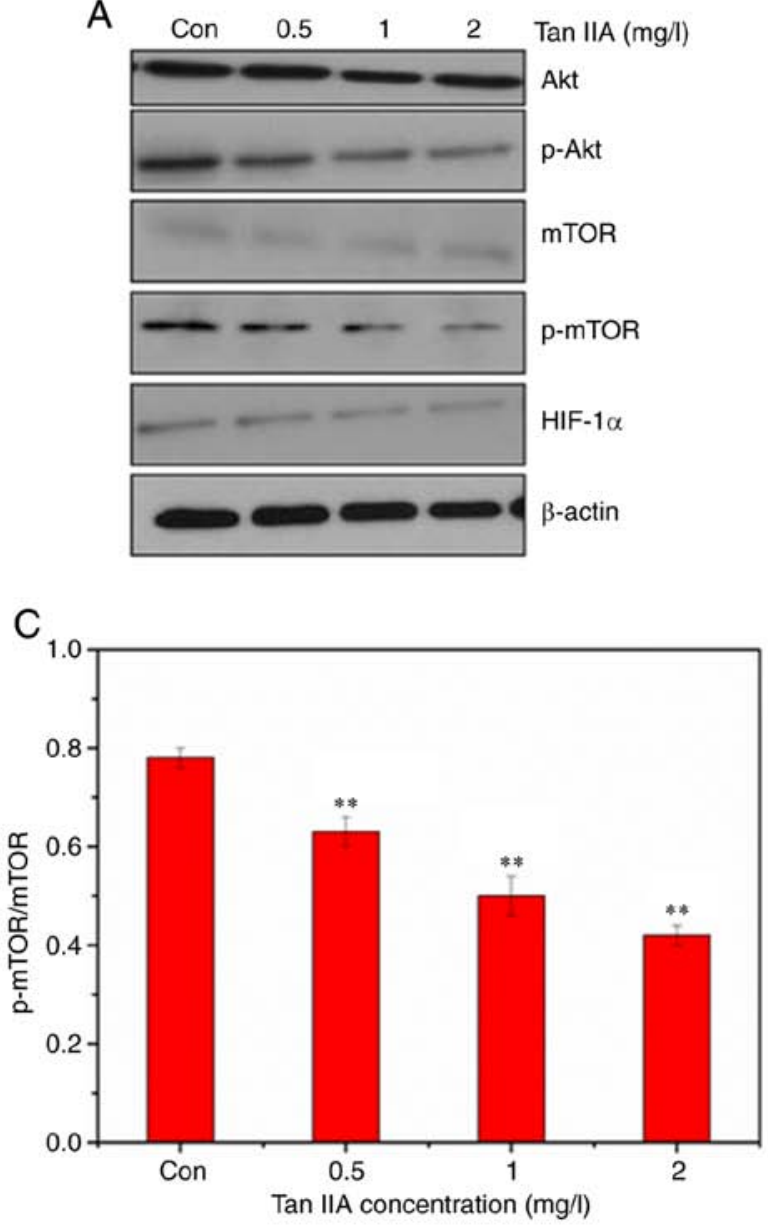

B

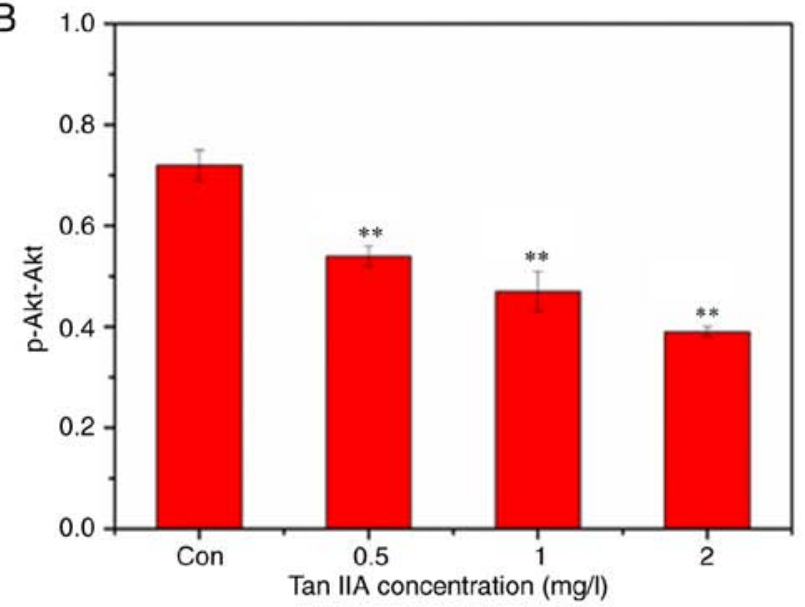

D

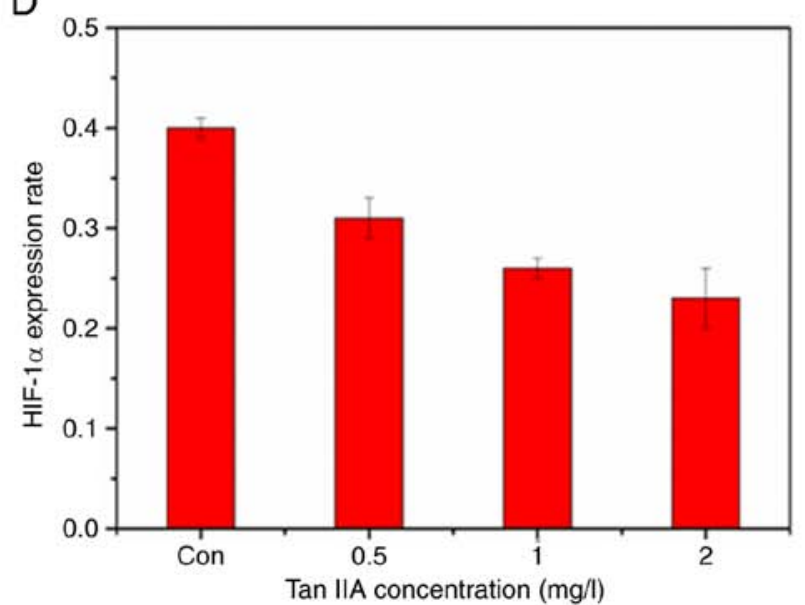

Figure 6. Tan IIA-induces changes in the expression of members of the Akt/mTOR signaling pathway and HIF-1 $\alpha$ in SiHa cells. (A) Following treatment with Tan IIA for $48 \mathrm{~h}$, the protein expression levels were determined using western blot analysis. (B) Relative expression of p-AKT/AKT. (C) Relative expression of p-mTOR/TOR. (D) Relative expression of HIF- $1 \alpha$ are presented as the mean $\pm \mathrm{SD}, \mathrm{n}=3 .{ }^{* *} \mathrm{P}<0.01$ compared with the control. Tan IIA, tanshinone IIA.

with Tan IIA, the tumor cells demonstrated regional necrosis, with shrunken cell volumes, nuclear condensation and clear interstitial edema occasionally infiltrated with inflammatory cells. 
A

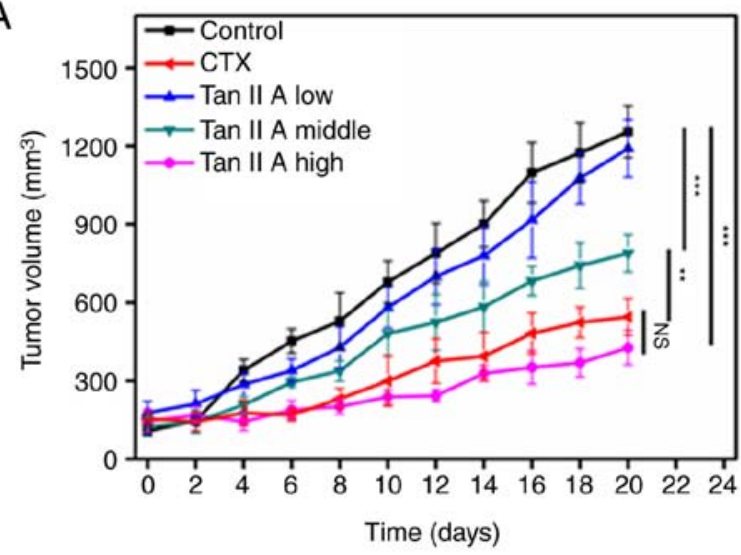

C

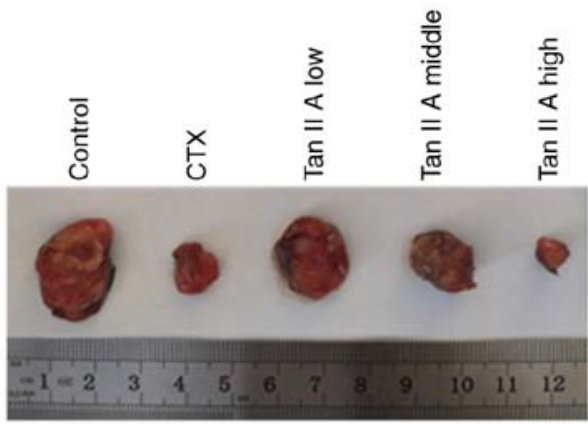

B
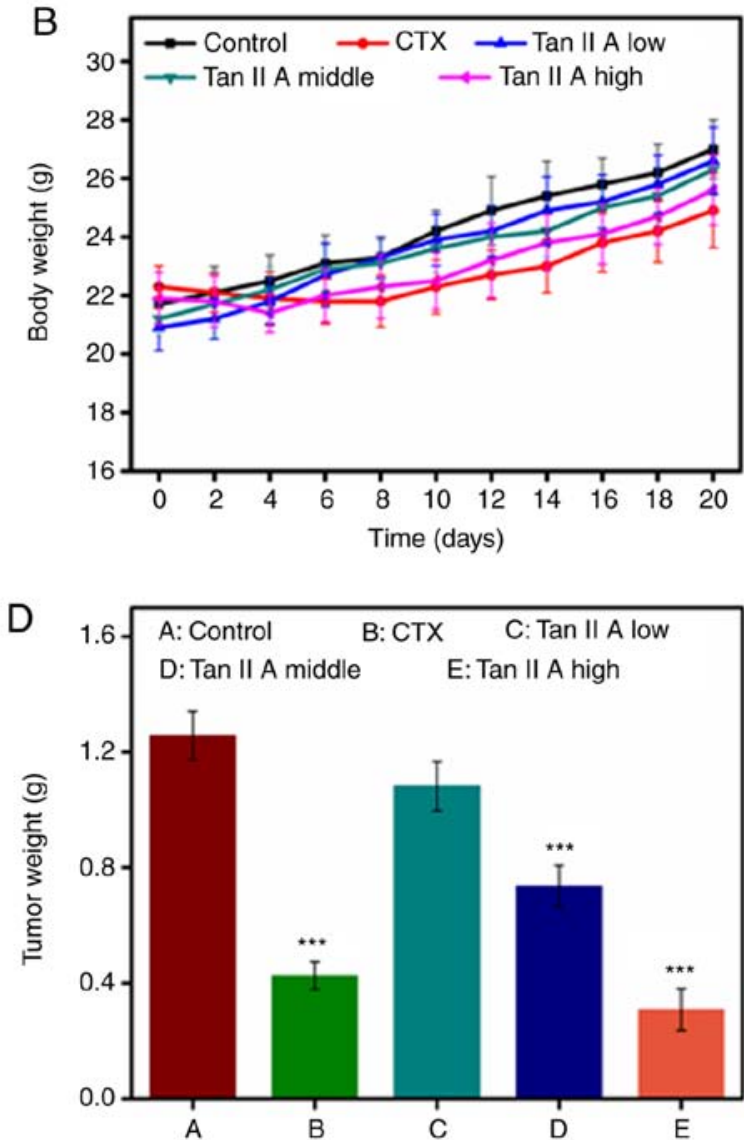

$\mathrm{E}$

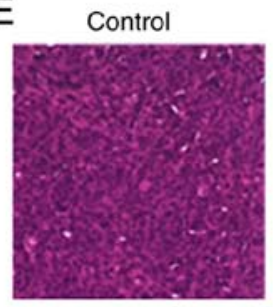

CTX

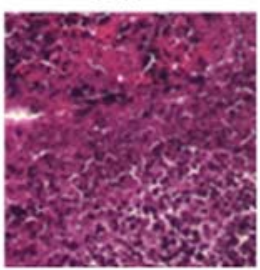

Tan II A low

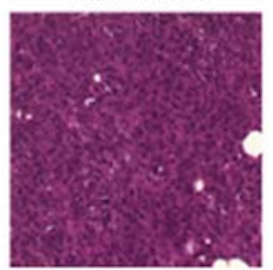

Tan II A middle

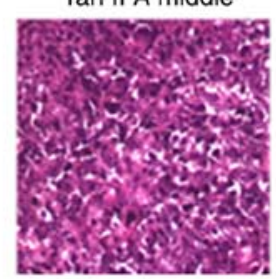

Tan II A high

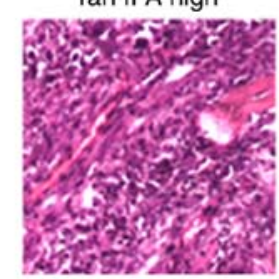

Figure 7. Antitumor effect of Tan IIA in U14-bearing mice. (A) Relative tumor volume measured during the course of treatment. (B) Plot the change in the body weight in U14 tumor-bearing mice during the course of treatment. (C) Representative images of the tumor in each group following completion of treatment. (D) Average weight of the tumor in each group. (E) Pathological examination of mice tumor tissues (x200). Data are presented as the mean $\pm \mathrm{SD}$, $\mathrm{n}=5$. ${ }^{* *} \mathrm{P}<0.01$ and ${ }^{* * * *} \mathrm{P}<0.001$ compared to the control. Tan IIA, tanshinone IIA; CTX, cyclophosphamide.

\section{Discussion}

The energy required for proliferation of cancer cells is obtained by glycolysis which is less efficient than aerobic oxidation of glucose (30). The use of glycolysis as the predominant source of energy is associated with certain factors, including upregulation of critical enzymes involved in glycolysis and glucose transporters. Concurrently, expression of enzymes involved in oxidative phosphorylation is downregulated. High glycolytic metabolism has been reported to be associated with resistance to apoptosis in cancer following treatment with anticancer drugs $(31,32)$. Tan IIA has been demonstrated to inhibit cell viability of cervical cancer by decreasing the expression of HPV oncogenes (26). However, the effect of Tan IIA on the inhibition of glycolysis in cervical cancer is still unknown. Therefore, in the present study, the effect of Tan IIA on inducing apoptosis and inhibiting glycolysis in cervical cancer and its possible mechanism were examined.
There are several subtypes of HPV, including high-risk subtypes which are associated with cancer development (33). More than 20 common subtypes of high-risk HPVs exist, with HPV16 being the most prevalent (34). The present study demonstrated that Tan IIA markedly decreased the cell viability of SiHa, HeLa, and C33a cervical cancer cells. Treatment with Tan IIA resulted in a greater decrease in cell viability in SiHa cells compared with HeLa and C33a cells. Therefore, SiHa cells (HPV 16-positive cells) were selected to determine the mechanism underlying the effects of Tan IIA. High-risk HPVs, including HPV16 and HPV18 result in the expression of oncogenes, E6 and E7. E6 and E7 combine to tumor suppressor p53 and $\mathrm{Rb}$, individually. This causes p53 degradation and loss of $\mathrm{Rb}$ products (35-37). The results of the present study revealed that following treatment Tan IIA, the mRNA and protein expression levels of E6 and E7 protein were decreased in SiHa cells. Abnormal cell proliferation and differentiation, and apoptotic imbalance are also important 
causes of tumorigenesis (38). A number of chemotherapeutic agents affect cancer cells, inducing apoptosis. Apoptotic cells display characteristic morphological changes, such as cell shrinkage, cytoplasmic vacuolation, chromatin condensation, nuclear fragmentation, and cell blebbing, to produce apoptotic bodies $(39,40)$. Hoechst 333258 staining results revealed typical apoptotic morphology in Tan IIA-treated SiHa cells. Fluorescence correlation spectroscopy revealed that the number of apoptotic cells increased as the concentration of Tan IIA was increased. The mechanism through which Tan IIA-induced apoptosis was examined, and the results revealed a marked decrease in Bcl-2 expression in the cells treated with Tan IIA, significantly increased Bax expression levels, and an increased $\mathrm{Bax} / \mathrm{Bcl}-2$ ratio (41). $\mathrm{Bcl}-2$ is an anti-apoptotic protein involved in the intrinsic apoptotic pathway which inhibits apoptosis by binding and subsequently inhibiting proapoptotic molecules, such as Bax and Bak (42). Therefore, changes in the Bax/Bcl-2 ratio may explain the increased rate of apoptosis in the Tan IIA-treated SiHa cells.

Apoptotic factors, such as cyto $c$, serve a crucial role in the mitochondrial apoptotic pathway, activating the activity of caspases in cancer cells. Chemotherapeutic agents and cytotoxic drugs frequently induce the release of cyto $c$ from mitochondria into the cytosol resulting in activation of caspase-9. Subsequently, pro-caspase-3 is transformed into its active form (caspase-3) by caspase-9-mediated cleavage. Poly-ADP ribose polymerase may be cleaved by caspase-3, causing DNA fragmentation and apoptosis (43). The results of the present study revealed that Tan IIA treatment resulted in the release of cyto $c$ from the mitochondria into the cytosol and the activation of caspase- 9 in SiHa cells. Subsequently, activated caspase- 9 impacted the downstream caspase-3 proenzyme and activated caspase-3, ultimately inducing apoptosis in $\mathrm{SiHa}$ cells.

The researcher and scientist Warburg revealed a phenomenon in which tumors prefer to utilize the energy which is supplied by glycolysis instead of aerobic oxidation of glucose even when there is an ample supply of oxygen. Anaerobic respiration in cancer cells leads to a considerable increase in the use of glucose $(44,45)$. The results of the present study revealed that Tan IIA treatment may suppress glucose uptake and extracellular lactic acid generation in SiHa cells. GLUT1, PKM2, and HK2 were all downregulated in the Tan IIA treatment group. GLUT1 is an important glucose transporter, which is a rate-limiting enzyme of glucose transport. Increased expression of GLUT1 is associated with proliferation, migration and invasion (46). HK2 and PKM2 isozyme expression is increased in a number of malignant types of cancer associated with a propensity for invasion and metastasis (47). The Akt/mTOR signaling is associated with hypoxia signaling transduction. At the translational level, the phosphorylation of Akt and mTOR can increase the hypoxia-induced expression of HIF-1 $\alpha$, which regulates intracellular glucose utilization and angiogenesis, and promotes stabilization and activation, eventually promoting tumor cell growth (48-50). The results of present study revealed that Tan IIA treatment decreased the expression of HIF-1 $\alpha$ and concurrently decreased the phosphorylation of Akt and mTOR in SiHa cells. This indicates that regulation of HIF-1 $\alpha$ by the Akt/mTOR pathway was involved in the inhibition of glycolysis when treated with Tan IIA.
In vitro, Tan IIA demonstrated significant antitumor effects in SiHa cells, and the possible mechanism was associated with inhibition of glycolysis. Therefore, the antitumor effect of Tan IIA in carcinoma-bearing mice was determined. The results of the present study revealed that carcinoma-bearing mice treated with Tan IIA presented with a significant reduction in the tumor volume and weight and there was no notable difference in the toxicity between the different groups of mice. The present study highlights the potential of Tan IIA as a therapeutic alternative.

In conclusion, the present study revealed that treatment with Tan IIA inhibited cell viability of cervical cancer $\mathrm{SiHa}$ cells and induced apoptosis. The possible mechanism was associated with the expression of the oncogenes E6 and E7, decreasing glycolysis through inhibition of the intracellular Akt/mTOR pathway and the associated HIF-1 $\alpha$ signaling. Tan IIA treatment increased apoptosis in SiHa cells, and this effect may be associated with inhibition of glycolysis.

\section{Acknowledgements}

Not applicable.

\section{Funding}

The present study was supported by the Project Agreement for Science and Technology Development, Jilin Province (nos. 20180101142JC,20190701062GH, 20130101157JC) and the Science and Technology Project of Jilin Provincial Department of Education (JJKH20190662KJ, JJKH20191062KJ, no. 2011286).

\section{Availability of data and materials}

All data generated or analyzed during this study are included in this published article.

\section{Authors' contributions}

ZL, WZhu and WZhang performed the experiments and participated in designing some experiments. XK and XC participated in the experiment of cell experiment and western blot analysis. XS and RZ performed the PCR and flow cytometry experiments, and WZhu, WZhang and RZ performed some of the in vivo experiments. WZhu wrote the manuscript. All authors have read and approved the manuscript and agree to be accountable for all aspects of the research in ensuring that the accuracy or integrity of any part of the work are appropriately investigated and resolved.

\section{Ethics approval and consent to participate}

All animal experiments were performed in compliance with the guidelines of the Ethics Committee for Animal Use and Care of Beihua University. This committee approved the experiments in the present study.

\section{Patient consent for publication}

Not applicable. 


\section{Competing interests}

The authors declare that they have no competing interests.

\section{References}

1. Lecavalier-Barsoum M, Chaudary N, Han K, Koritzinsky M, Hill R and Milosevic M: Targeting the CXCL12/CXCR4 pathway and myeloid cells to improve radiation treatment of locally advanced cervical cancer. Int J Cancer 143: 1017-1028, 2018.

2. Testa U, Petrucci E, Pasquini L, Castelli G and Pelosi E: Ovarian cancers: Genetic abnormalities, tumor heterogeneity and progression, clonal evolution and cancer stem cells. Medicines (Basel) 5: pii: E16, 2018.

3. Scheffner M, Werness BA, Huibregtse JM, Levine AJ and Howley PM: The E6 oncoprotein encoded by human papillomavirus types 16 and 18 promotes the degradation of p53. Cell 63: 1129-1136, 1990.

4. Wardak S: Human papillomavirus (HPV) and cervical cancer. Med Dosw Mikrobiol 68: 73-84, 2016.

5. Suh DH, Kim M, Kim K, Kim HJ, Lee KH and Kim JW: Major clinical research advances in gynecologic cancer in 2016: 10-year special edition. J Gynecol Oncol 28: e45, 2017.

6. Cancer Genome Atlas Research Network; Albert Einstein College of Medicine; Analytical Biological Services; Barretos Cancer Hospital; Baylor College of Medicine; Beckman Research Institute of City of Hope; Buck Institute for Research on Aging; Canada's Michael Smith Genome Sciences Centre; Harvard Medical School; Helen F. Graham Cancer Center \& Research Institute at Christiana Care Health Services, et al: Integrated genomic and molecular characterization of cervical cancer. Nature 543: 378-384, 2017.

7. Wentzensen N, Schiffman M, Palmer T and Arbyn M: Triage of HPV positive women in cervical cancer screening. J Clin Virol 76 (Suppl 1): S49-S55, 2016.

8. Fox BW: Medicinal plants in tropical medicine. 2. Natural products in cancer treatment from bench to the clinic. Trans R Soc Trop Med Hyg 85: 22, 1991.

9. Pokrzywa CJ,AbbottDE,MatkowskyjKA, Ronnekleiv-Kelly SM, Winslow ER, Weber SM and Fisher AV: Natural history and treatment trends in pancreatic cancer subtypes. J Gastrointest Surg 23: 768-778, 2019.

10. Guo J, Ma X, Cai Y, Ma Y, Zhan Z, Zhou YJ, Liu W, Guan M, Yang J, Cui G, et al: Cytochrome P450 promiscuity leads to a bifurcating biosynthetic pathway for tanshinones. New Phytol 210: 525-534, 2016.

11. Li C, Han X, Hong Z, Wu J and Bao L: The interplay between autophagy and apoptosis induced by tanshinone IIA in prostate cancer cells. Tumour Biol 37: 7667-7674, 2016.

12. Liao P, Hemmerlin A, Bach TJ and Chye ML: The potential of the mevalonate pathway for enhanced isoprenoid production. Biotechnol Adv 34: 697-713, 2016.

13. Zhang Y, Jiang P, Ye M, Kim SH, Jiang C and Lü J: Tanshinones: Sources, pharmacokinetics and anti-cancer activities. Int J Mol Sci 13: 13621-13666, 2012.

14. Fan G, Jiang X, Wu X, Fordjour PA, Miao L, Zhang H, Zhu Y and Gao X: Anti-inflammatory activity of tanshinone IIA in LPS-Stimulated RAW264.7 macrophages via miRNAs and TLR4-NF- $\kappa$ B pathway. Inflammation 39: 375-384, 2016.

15. Li Q, Shen L, Wang Z, Jiang HP and Liu LX: Tanshinone IIA protects against myocardial ischemia reperfusion injury by activating the PI3K/Akt/mTOR signaling pathway. Biomed Pharmacother 84: 106-114, 2016.

16. Wang S, Cang S and Liu D: Third-generation inhibitors targeting EGFR T790M mutation in advanced non-small cell lung cancer. J Hematol Oncol 9: 34, 2016.

17. Cui ZT, Liu JP and Wei WL: The effects of tanshinone IIA on hypoxia/reoxygenation-induced myocardial microvascular endothelial cell apoptosis in rats via the JAK2/STAT3 signaling pathway. Biomed Pharmacother 83: 1116-1126, 2016.

18. Yano S, Takehara K, Ming Z, Tan Y, Han Q, Li S, Bouvet M, Fujiwara $\mathrm{T}$ and Hoffman RM: Tumor-specific cell-cycle decoy by Salmonella typhimurium A1-R combined with tumor-selective cell-cycle trap by methioninase overcome tumor intrinsic chemoresistance as visualized by FUCCI imaging. Cell Cycle 15: $1715-1723,2016$

19. Parr R, Harbottle A, Jakupciak JP and Singh G: Mitochondria and cancer. Biomed Res Int 2013: 763703, 2013.
20. Zhao E, Maj T, Kryczek I, Li W, Wu K, Zhao L, Wei S, Crespo J, Wan S, Vatan L, et al: Cancer mediates effector T cell dysfunction by targeting microRNAs and EZH2 via glycolysis restriction. Nat Immunol 17: 95-103, 2016.

21. Wen Z, Zhang SL, Hu X and Tam KY: Targeting tumor metabolism for cancer treatment: Is pyruvate dehydrogenase kinases (PDKs) a viable anticancer target? Int J Biol Sci 11: 1390-1400, 2015.

22. Choe M, Brusgard JL, Chumsri S, Bhandary L, Zhao XF, Lu S, Goloubeva OG, Polster BM, Fiskum GM, Girnun GD, et al: The RUNX2 transcription factor negatively regulates SIRT6 expression to alter glucose metabolism in breast cancer cells. J Cell Biochem 116: 2210-2226, 2015.

23. Lu J, Chen M, Gao S, Yuan J, Zhu Z and Zou X: LY294002 inhibits the Warburg effect in gastric cancer cells by downregulating pyruvate kinase M2. Oncol Lett 15: 4358-4364, 2018.

24. Lu W, Hu Y, Chen G, Chen Z, Zhang H, Wang F, Feng L, Pelicano $\mathrm{H}$, Wang $\mathrm{H}$, Keating MJ, et al: Novel role of NOX in supporting aerobic glycolysis in cancer cells with mitochondrial dysfunction and as a potential target for cancer therapy. PLoS Biol 10: e1001326, 2012.

25. Pan TL, Wang PW, Hung YC, Huang CH and Rau KM: Proteomic analysis reveals tanshinone IIA enhances apoptosis of advanced cervix carcinoma CaSki cells through mitochondria intrinsic and endoplasmic reticulum stress pathways. Proteomics 13: 3411-3423, 2013.

26. Radha M, Farrukh A, Jeyaprakash J and Gupta RC: Tanshinone IIA inhibits viral oncogene expression leading to apoptosis and inhibition of cervical cancer. Cancer Lett 356: 536-546, 2015.

27. Mosmann T: Rapid colorimetric assay for cellular growth and survival: Application to proliferation and cytotoxicity assays. J Immunol Methods 65: 55-63, 1983.

28. Livak KJ and Schmittgen TD: Analysis of relative gene expression data using real-time quantitative PCR and the 2(-Delta Delta C(T)) method. Methods 25: 402-408, 2001.

29. Yu W, Yang Z, Huang R, Min Z and Ye M: SIRT6 promotes the Warburg effect of papillary thyroid cancer cell BCPAP through reactive oxygen species. Onco Targets Ther 12: 2861-2868, 2019.

30. Gasparre G, Porcelli AM, Lenaz G and Romeo G: Relevance of mitochondrial genetics and metabolism in cancer development. Cold Spring Harb Perspect Biol 5: pii: a011411, 2013.

31. Mathupala SP, Rempel A and Pedersen PL: Aberrant glycolytic metabolism of cancer cells: A remarkable coordination of genetic, transcriptional, post-translational, and mutational events that lead to a critical role for type II hexokinase. J Bioenerg Biomembr 29: 339-343, 1997.

32. Vaz CV, Marques R, Alves MG, Oliveira PF, Cavaco JE, Maia CJ and Socorro S: Androgens enhance the glycolytic metabolism and lactate export in prostate cancer cells by modulating the expression of GLUT1, GLUT3, PFK, LDH and MCT4 genes. J Cancer Res Clin Oncol 142: 5-16, 2016.

33. Protzel C, Knoedel J, Zimmermann U, Woenckhaus C, Poetsch $\mathrm{M}$ and Giebel J: Expression of proliferation marker Ki67 correlates to occurrence of metastasis and prognosis, histological subtypes and HPV DNA detection in penile carcinomas. Histol Histopathol 22: 1197-1204, 2007.

34. Varier I, Keeley BR, Krupar R, Patsias A, Dong J, Gupta N, Parasher AK, Genden EM, Miles BA, Teng M, et al: Clinical characteristics and outcomes of oropharyngeal carcinoma related to high-risk non-human papillomavirus16 viral subtypes. Head Neck 38: 1330-1337, 2016.

35. Ristriani T, Fournane S, Orfanoudakis G, Travé G and Masson M: A single-codon mutation converts HPV16 E6 oncoprotein into a potential tumor suppressor, which induces p53-dependent senescence of HPV-positive HeLa cervical cancer cells. Oncogene 28: 762-772, 2009.

36. Termini L, Boccardo E, Esteves GH, Hirata R Jr, Martins WK, Colo AE, Neves EJ, Villa LL and Reis LF: Characterization of global transcription profile of normal and HPV-immortalized keratinocytes and their response to TNF treatment. BMC Med Genomics 1: 29-29, 2008.

37. Yu Y, Liu X, Yang Y, Zhao X, Xue J, Zhang W and Yang A: Effect of FHIT loss and p53 mutation on HPV-infected lung carcinoma development. Oncol Lett 10: 392-398, 2015.

38. Hirokawa M, Kawabata Y and Miura AB: Dysregulation of apoptosis and a novel mechanism of defective apoptotic signal transduction in human B-cell neoplasms. Leuk Lymphoma 43: 243-249, 2002.

39. Aschoff AP, Günther E and Jirikowski GF: Tissue transglutaminase in the small intestine of the mouse as a marker for apoptotic cells. Colocalization with DNA fragmentation. Histochem Cell Biol 113: 313-317, 2000. 
40. Cha Y, Park DW, Lee CH, Baek SH, Kim SY, Kim JR and Kim JH: Arsenic trioxide induces apoptosis in human colorectal adenocarcinoma HT-29 cells through ROS. Cancer Res Treat 38: 54-60, 2006

41. Zhu W, Zhang W, Xu N, Li Y, Xu J, Zhang H, Li Y, Lv S, Liu W and Wang H: Dihydroartemisinin induces apoptosis and downregulates glucose metabolism in JF-305 pancreatic cancer cells. Rsc Adv 8: 20692-20700, 2018.

42. Zhu W, Zhang W, Li Y, et al: Possible mechanism of apoptosis induced by microwave radiation in human cervical carcinoma cell HeLa. Radiat Protect 22: 378-2258, 2013.

43. Wang Y, Gao W, Shi X, Ding J, Liu W, He H, Wang K and Shao F: Chemotherapy drugs induce pyroptosis through caspase-3 cleavage of a gasdermin. Nature 547: 99-103, 2017.

44. Hou X, Hongzhi DU and Yuan S: Research progress of tumor metabolism for antitumor drugs. Cancer Res Prev Treat 44: 231-235, 2017.

45. Zhivotovsky B and Orrenius S: The Warburg effect returns to the cancer stage. Semin Cancer Biol 19: 1-3, 2009.

46. North PE, Waner M, Mizeracki A and Mihm MC Jr: GLUT1: A newly discovered immunohistochemical marker for juvenile hemangiomas. Hum Pathol 31: 11-22, 2000.
47. Qiu P, Man S, Yang H, Liu Y, Liu Z, Ma L, Yu P and Gao W: Metabolic regulatory network alterations reveal different therapeutic effects of cisplatin and Rhizoma paridis saponins in Lewis pulmonary adenoma mice. RSC Adv 6: 115029-115038, 2016.

48. Dayan F, Bilton RL, Laferrière J, Trottier E, Roux D, Pouyssegur J and Mazure NM: Activation of HIF-1alpha in exponentially growing cells via hypoxic stimulation is independent of the Akt/mTOR pathway. J Cell Physiol 218: 167-174, 2009.

49. Wang F, Zhang W, Guo L, Cheng J, Liu P and Chen B: Gambogic acid suppresses hypoxia-induced HIF-1 $\alpha$ /VEGF expression via inhibiting PI3K/Akt/mTOR pathway in multiple myeloma cells. Blood 124: 5230, 2014.

50. Yeh YH, Hsiao HF, Yeh YC, Chen TW and Li TK: Inflammatory interferon activates HIF-1 $\alpha$-mediated epithelial-to-mesenchymal transition via PI3K/AKT/mTOR pathway. J Exp Clin Cancer Res 37: 70, 2018.

(c) (i) () This work is licensed under a Creative Commons Attribution-NonCommercial-NoDerivatives 4.0 International (CC BY-NC-ND 4.0) License. 